\title{
Article \\ Design and Analysis of a High Torque Density Hybrid Permanent Magnet Excited Vernier Machine
}

\author{
Mei Kang, Liang Xu *, Jinghua Ji and Xuhui Zhu
}

check for updates

Citation: Kang, M.; Xu, L.; Ji, J.; Zhu, $X$. Design and Analysis of a High Torque Density Hybrid Permanent Magnet Excited Vernier Machine. Energies 2022, 15, 1723. https:// doi.org/10.3390/en15051723

Academic Editor: Gerard-Andre Capolino

Received: 6 January 2022

Accepted: 23 February 2022

Published: 25 February 2022

Publisher's Note: MDPI stays neutral with regard to jurisdictional claims in published maps and institutional affiliations.

Copyright: (C) 2022 by the authors. Licensee MDPI, Basel, Switzerland. This article is an open access article distributed under the terms and conditions of the Creative Commons Attribution (CC BY) license (https:// creativecommons.org/licenses/by/ $4.0 /)$.

\author{
School of Electrical and Information Engineering, Jiangsu University, Zhenjiang 212013, China; \\ kangmei@ujs.edu.cn (M.K.); jjh@ujs.edu.cn (J.J.); zhuxuhui@ntu.edu.cn (X.Z.) \\ * Correspondence: xuliang0511@ujs.edu.cn
}

\begin{abstract}
Permanent magnet (PM) excited vernier machines capable of high torque density have good potential for electric vehicles while requiring high rare earth PM consumption. To achieve a high torque density at a reasonable material cost, hybrid PM excited vernier machines incorporating both expensive rare earth and low-cost ferrite magnets are investigated in this paper. Various combinations of PM arrangements for the hybrid permanent magnet excited vernier machine are investigated to acquire low cost and superior torque density. The best solution obtained is that the PM on the stator adopts rare earth material while the rotor uses ferrite. Furthermore, the PMs on the stator are arranged in an iron-cored Halbach array, which can reduce leakage flux and enhance flux density effectively and the ferrite PMs are used in the rotor, therefore, high-temperature demagnetization is avoided. Then, the reluctance torque and the cogging torque can offset each other effectively, which is beneficial to reducing the torque ripple and smoothing the electromagnetic torque. Finally, a prototype is manufactured and tested to verify the correctness of the theoretical analysis.
\end{abstract}

Keywords: vernier machine; hybrid permanent magnet excited; cogging torque; torque ripple

\section{Introduction}

With the development of industrial technology, high-torque electrical machines attract more and more attention in direct drive applications [1-4]. The conventional electrical machine drive system includes a machine and a gearbox. Therefore, the volume of the system will be increased. Moreover, the gearbox often needs maintenance, while it also has the disadvantages of large noise and vibration. To make full use of system space and improve the torque density, many dual-sided permanent magnet (PM) machines have been proposed [5-7]. However, the dual-sided structure increases the difficulties of machine structure, processing and control. Recently, many researchers have focused on magneticallygeared PM machines and PM vernier (PMV) machines, which provide high torque density due to the principle of the so-called magnetic gear effect. Particularly, compared with the traditional dual-sided PM machines and magnetically-geared PM machines, the PMV machines have a simpler structure that is easier to manufacture [8-16]. Thus, the PMV machine is becoming a hot topic in many fields, such as wind power generation, hybrid electric vehicles, and so on [17-19].

The conception of the PMV machine was proposed in 1995 [20]. The most notable feature of the machine is that it can obtain high torque at a low speed. This remarkable feature gives the PMV machine a great prospect of application. To improve the torque density, many new kinds of PMV machines have been proposed. It was shown that the torque density of the PMV machine can be improved by using different forms of PM arrangement [21-24]. However, the cost of these machines is also increased due to the increase in the price of rare earth PM consumption [25-28]. In order to reduce the cost of the machine, a lot of electrical machines with less rare earth PM, ferrite, or even no magnets, were proposed in [29-33]. Additionally, a new kind of PMV machine using the 
low-cost ferrite was proposed in [34]. However, since the performance of ferrite is much poorer than $\mathrm{NdFeB}$, the torque of the machine with ferrite is limited. In addition, most of the existing studies are mostly based on the rotor PM or stator PM vernier machine. Although the PMV machine with PM in both the stator and rotor can make full use of the space and improve the torque density of the machine, it will greatly increase the amount of the PMs [35-41]. In [37], a double-sided PMV machine was proposed to apply in a servo system. The cogging torque and torque ripple are investigated to meet the application requirement. In [39], the torque generation mechanism of a dual side PMV is revealed from the perspective of magnetic field modulation. However, the cost of PM material is ignored. Particularly, if only the rare earth PM material is employed in the machine, it is obvious that the cost of the machine will also be greatly increased. The PMV machine only excited by ferrite has the advantage of low cost, while it suffers from poor torque density. Therefore, in order to achieve a high torque density at a reasonable cost, a hybrid permanent-magnet excited vernier (HPMV) machine incorporating expansive rare earth and inexpensive ferrite magnets is a compromise solution.

In this paper, a new HPMV machine will be proposed and investigated. The topology and fundamental operation principle will be illustrated in Section 2. Section 3 will be committed to analyzing the parameters in the process of the machine design. The steady-state characteristics will be calculated by finite element method (FEM) in Section 4, including flux linkage, back electromotive force (back-EMF), and inductance and a torque density comparison between the proposed machine and the conventional one will be carried out. In Section 5 , the prototype machine is manufactured and experimented with. The conclusions are drawn in Section 6.

\section{Topology and Operation Principle}

\subsection{Topology}

Figure 1 shows the topology of the proposed HPMV machine which is composed of a stator and a rotor. The rotor is designed as a simple iron core with salient poles and ferrite magnets placed in the slots of the rotor. The stator consists of the iron core with split teeth, armature windings and $\mathrm{NdFeB}$ magnets which are mounted on the inner surface of the stator split teeth. The PMs in the stator are arranged with an iron-cored Halbach array. The magnetization directions of the PMs are shown in Figure 1. It can be seen that the radial magnetized PM of the stator is sandwiched by the two tangential magnetized PMs. The magnetization directions of the ferrite in the rotor are the same as the radial magnetized PMs in the stator PM arrays. The radial magnetized PMs are used to produce the main flux. The tangential magnetized PMs can effectively alleviate reducing fringing leakage flux, hence increasing the torque capability. Furthermore, the windings are an adopted concentrated connection in this machine so as to reduce the end length of windings and copper loss.

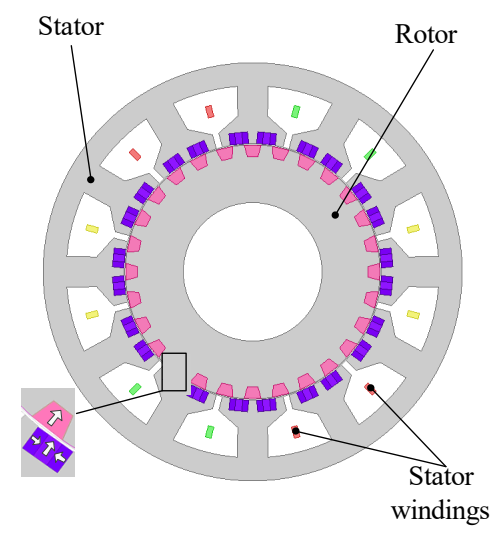

Figure 1. Topology of the proposed machine. 


\subsection{Operation Principle}

The operation principle of the proposed machine is similar to the conventional PMV machine. The key difference is that the rare earth PMs with the iron-cored Halbach arrays are adopted in the stator and the ferrites are mounted on the rotor. Both the stator and the rotor are salient structures. Both the rotor and the stator teeth can be regarded as modulation poles.

The operation principle of the proposed HPMV machine is shown in Figure 2. The flux linkages marked red are produced by the stator PMs, while the blue ones are produced by the rotor PMs. It is obvious that the flux linkages due to the stator PMs and rotor PMs can overlap to enhance the magnetic field. In order to take advantage of the flux-modulation effect, the HPMV machine should satisfy:

$$
p_{r}=N_{s} \pm p_{w}
$$

where $N_{s}, p_{r}$ and $p_{w}$ represent the number of field modulation poles, rotor pole-pairs and winding pole-pairs, respectively. The high-speed rotating field generated by the stator windings is modulated into the low-speed rotating field in the air gap, which in turn synchronously rotates with the PM rotor, thus offering a steady torque. The corresponding high-to-low speed ratio $G_{r}$ is governed by:

$$
G_{r}=\left(N_{s}-p_{w}\right) / p_{w}
$$

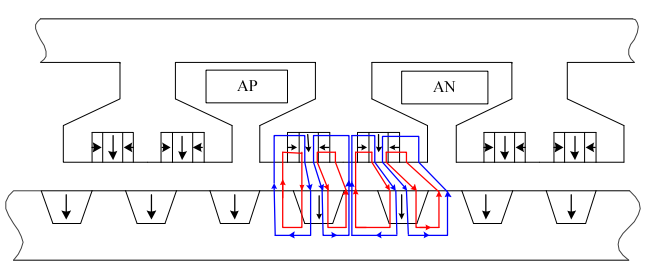

(a)

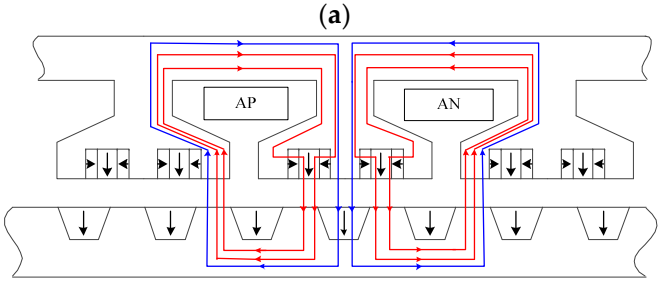

(b)

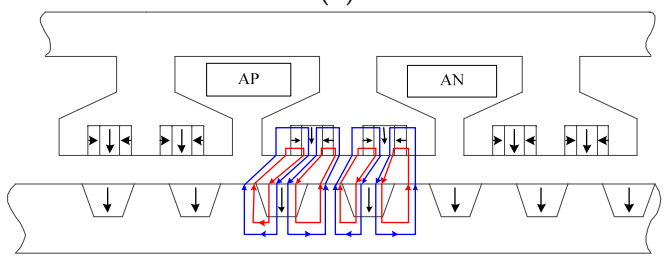

(c)

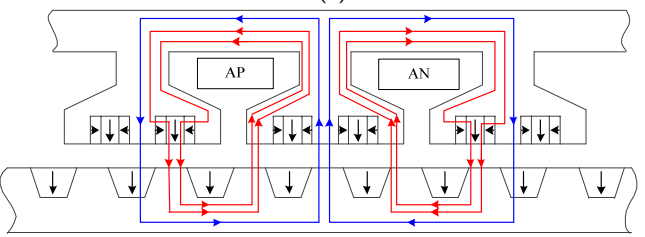

(d)

Figure 2. Operation principle of the proposed machine. (a) $0^{\circ}$. (b) $90^{\circ}$. (c) $180^{\circ}$. (d) $270^{\circ}$.

The magnetic fields excited by PMs can be modulated by the modulation teeth in the conventional PMV machines. The proposed HPMV machine provides the teeth in the stator and rotor with multiple modulations. For the stator or the rotor side, the magnetic field generated by one side of the PMs is modulated by the teeth on another side. 
To further clarify the operation principle of the proposed machine, the following assumptions are made. The permeability of the cores is infinite. According to the coordinate system, the variation of the air-gap magnetic field is only considered along the circumferential direction. The magneto-motive forces (MMFs) generated by the stator PM $F_{s}\left(\theta_{s}\right)$ and rotor $\operatorname{PM} F_{r}\left(\theta_{r}\right)$ can be expressed as:

$$
\begin{gathered}
F_{s}\left(\theta_{s}\right)=\sum_{n=1}^{\infty} F_{n} \cos \left(n p_{s} \theta_{s}\right) \\
F_{r}\left(\theta_{r}\right)=\sum_{m=1}^{\infty} F_{m} \cos \left(m p_{r} \theta_{r}\right)
\end{gathered}
$$

where $m$ and $n$ are the positive integer, $F_{n}$ is the MMF amplitudes of $n$-th order harmonic generated by stator PMs, and $F_{m}$ is the MMF amplitudes of $m$-th order harmonic generated by the rotor PMs. $p_{s}$ and $p_{r}$ are the number of pole pairs in the stator and rotor, respectively. $\theta_{s}$ and $\theta_{r}$ are the relative angles of the stator and rotor, respectively.

The permeance of the stator $\Lambda\left(\theta_{s}, t\right)$ and rotor teeth $\Lambda\left(\theta_{r}, t\right)$ can be expressed as:

$$
\begin{aligned}
& \Lambda\left(\theta_{s}, t\right)=\Lambda_{0}+\sum_{k=1}^{\infty} \Lambda_{k} \cos \left[k N_{s}\left(\theta_{s}-\omega t-\theta_{0}\right)\right] \\
& \Lambda\left(\theta_{r}, t\right)=\Lambda_{0}^{\prime}+\sum_{k=1}^{\infty} \Lambda_{k}^{\prime} \cos \left[k N_{r}\left(\theta_{r}-\omega t-\theta_{0}^{\prime}\right)\right]
\end{aligned}
$$

where $k$ is the positive integer, $\Lambda_{0}$ and $\Lambda_{0}^{\prime}$ are the dc components of the stator and rotor permeance. $\Lambda_{k}$ and $\Lambda_{k}^{\prime}$ are the amplitude of $k$-th order harmonics of the stator and rotor permeance, respectively. $N_{r}$ and $N_{s}$ are the number of modulation teeth in the rotor and stator, respectively. $\omega$ is the rotational angular velocity of the rotor. $\theta_{0}$ and $\theta_{0}^{\prime}$ are the original angles of the stator and rotor.

The flux densities generated by the stator $\mathrm{PM} B\left(\theta_{s}, t\right)$ and the rotor $\mathrm{PM} B\left(\theta_{r}, t\right)$ are given by:

$$
\begin{aligned}
B\left(\theta_{s}, t\right)= & F_{s}\left(\theta_{s}\right) \Lambda\left(\theta_{r}, t\right) \\
= & \sum_{n=1}^{\infty} F_{n} \Lambda_{0}^{\prime} \cos \left(n p_{s} \theta_{s}\right)+\sum_{n=1}^{\infty} \sum_{k=1}^{\infty} F_{n} \Lambda_{k}^{\prime} \\
& \times \cos \left(n p_{s} \theta_{s}\right) \cos \left[k N_{r}\left(\theta_{r}-\omega t-\theta_{0}^{\prime}\right)\right] \\
B\left(\theta_{r}, t\right)= & F_{r}\left(\theta_{r}\right) \Lambda\left(\theta_{s}, t\right) \\
= & \sum_{m=1}^{\infty} F_{m} \Lambda_{0} \cos \left(m p_{r} \theta_{r}\right)+\sum_{m=1}^{\infty} \sum_{k=1}^{\infty} F_{m} \Lambda_{k} \\
& \times \cos \left(m p_{r} \theta_{r}\right) \cos \left[k N_{r}\left(\theta_{s}-\omega t-\theta_{0}\right)\right]
\end{aligned}
$$

Thus, the air-gap flux density $B\left(\theta_{s}, \theta_{r}, t\right)$ can be written as:

$$
\begin{aligned}
B\left(\theta_{s}, \theta_{r}, t\right) & =B\left(\theta_{s}, t\right)+B\left(\theta_{r}, t\right) \\
& =\sum_{n=1}^{\infty} F_{n} \Lambda_{0}^{\prime} \cos \left(n p_{s} \theta_{s}\right)+\sum_{m, o d d}^{\infty} F_{m} \Lambda_{0} \cos \left(m p_{r} \theta_{r}\right) \\
& +\frac{1}{2} \sum_{n=1}^{\infty} \sum_{k=1}^{\infty} F_{n} \Lambda_{k}^{\prime} \cos \left[\theta_{s}\left(n p_{s}+k N_{s}\right)-k N_{s}\left(\omega t+\theta_{0}^{\prime}\right)\right] \\
& +\frac{1}{2} \sum_{n=1}^{\infty} \sum_{k=1}^{\infty} F_{n} \Lambda_{k}^{\prime} \cos \left[\theta_{s}\left(n p_{s}-k N_{s}\right)+k N_{s}\left(\omega t+\theta_{0}^{\prime}\right)\right] \\
& +\frac{1}{2} \sum_{m=1}^{\infty} \sum_{k=1}^{\infty} F_{m} \Lambda_{k} \cos \left[\theta_{r}\left(m p_{r}+k N_{r}\right)-k N_{r}\left(\omega t+\theta_{0}\right)\right] \\
& +\frac{1}{2} \sum_{m=1}^{\infty} \sum_{k=1}^{\infty} F_{m} \Lambda_{k} \cos \left[\theta_{r}\left(m p_{r}-k N_{r}\right)+k N_{r}\left(\omega t+\theta_{0}\right)\right]
\end{aligned}
$$


In this machine design, $p_{s}$ and $N_{s}$ are selected to be 8 and 36, respectively. The key data of the proposed machine are listed in Table 1. Due to the salient pole teeth both on the stator and rotor, the machine has multiple modulations. There are many kinds of harmonics in the air-gap magnetic field, which are shown in Figure 3.

Table 1. Machine parameters.

\begin{tabular}{cc}
\hline Item & Parameter \\
\hline Phase, $N_{\mathrm{ph}}$ & 3 \\
Number of slots, $S$ & 12 \\
Number of rotor pole pairs, $Z$ & 28 \\
Number of armature winding pole pairs, $p$ & 8 \\
Outside stator diameter, $D_{\text {so }}(\mathrm{mm})$ & 145 \\
Outside rotor diameter, $D_{\text {ro }}(\mathrm{mm})$ & 88 \\
Air-gap length, $\delta(\mathrm{mm})$ & 0.5 \\
Effective axial length, $l_{\text {stk }}(\mathrm{mm})$ & 60 \\
\hline
\end{tabular}

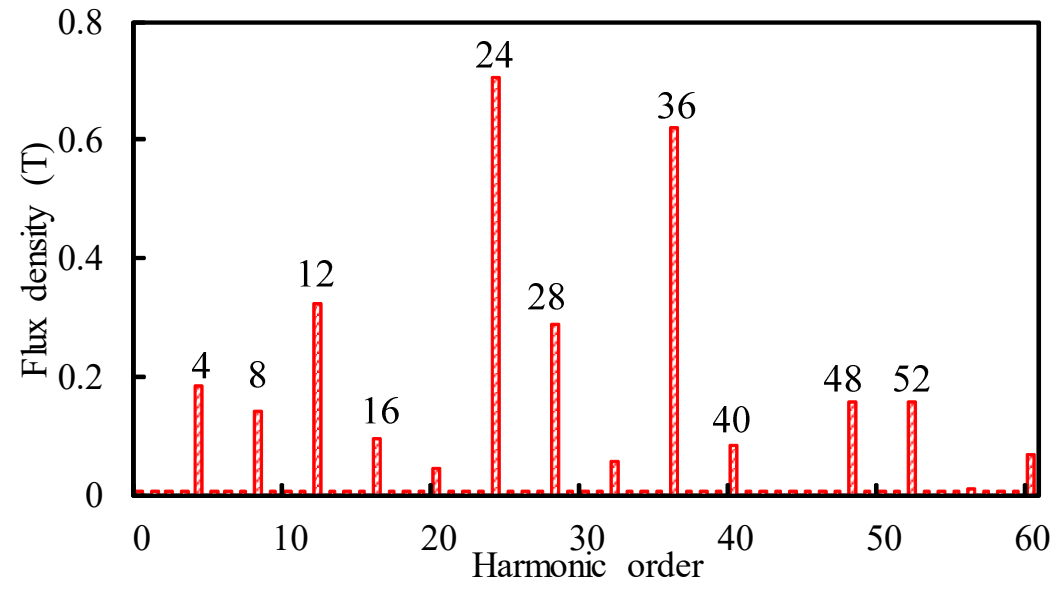

Figure 3. Fourier analysis of magnetic flux density in air gap.

\section{Machine Design}

The electromagnetic analysis is investigated to find the most suitable structure that can improve performance. All the optimizations are based on the back-EMF and torque ripple. The combination of PM materials is one of the most important factors affecting the performance of the machine. Therefore, the optimal combination should be confirmed first before the optimization of the structure parameters.

Figure 4 exhibits eight combinations of the stator PMs and the rotor PMs in the machine. The purple parts and pink parts represent the NdFeB and Y30 magnet materials, respectively. The Y30 is one of the ferrite PMs, which has the advantages of price and anti-demagnetization at high temperatures. Therefore, it is meaningful to find out the arrangements of the PMs to reduce the cost and improve the performance.

Figure 5 compares the back-EMF amplitudes and the consumptions of the PMs of the eight types. As shown, the back-EMF amplitude greatly depends on the consumption of NdFeB. The different PM combinations are accompanied by the different NdFeB consumptions. Figure 6 shows the ratios of the NdFeB volume and the back-EMF with the eight types. It can be found that the back-EMF increases with the increase in the consumption of NdFeB. Figure 7 shows the cogging torque and back-EMF of the eight types of PM arrays. It can be seen that the changing trend of cogging torque is different from that of the back-EMF. 


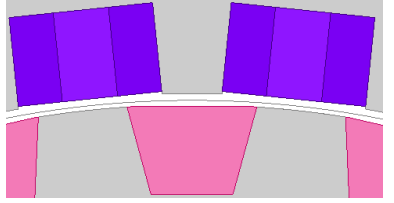

(a)

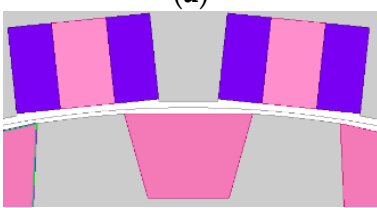

(c)

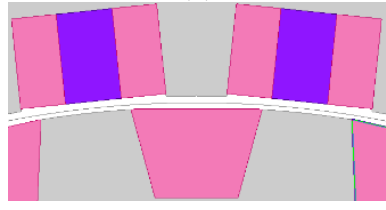

(e)

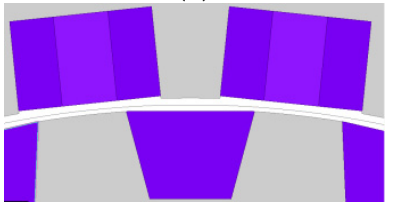

(g)

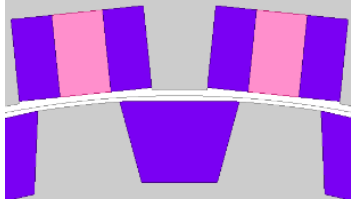

(b)

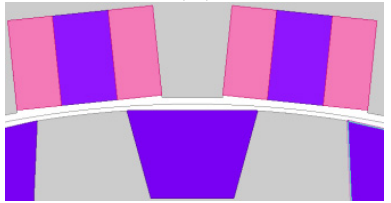

(d)

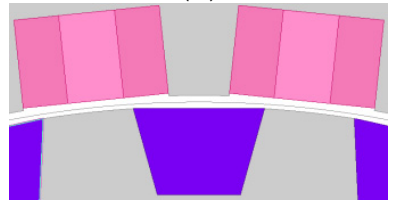

(f)

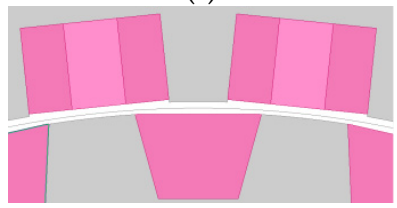

(h)

Figure 4. Combinations of NdFeB and ferrite PMs. (a) Type 1. (b) Type 2. (c) Type 3. (d) Type 4. (e) Type 5. (f) Type 6. (g) Type 7. (h) Type 8.

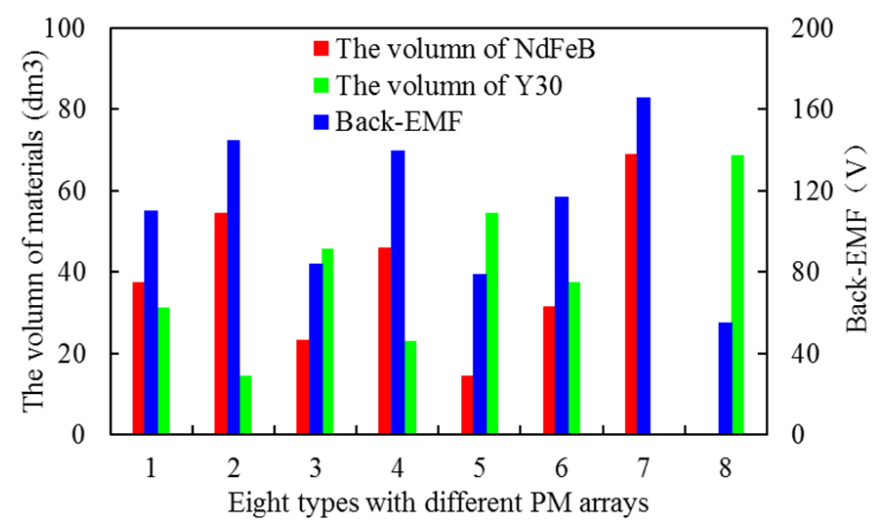

Figure 5. Volume of PMs and back-EMF of the eight types with different materials.

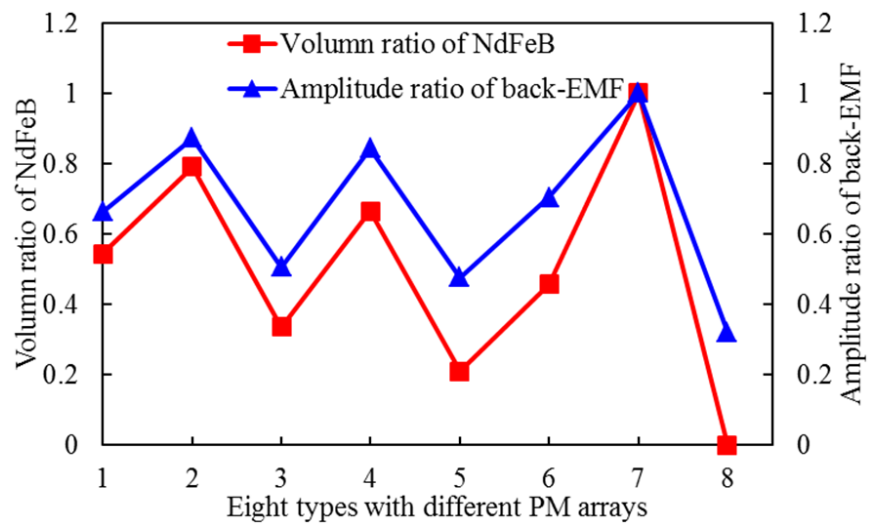

Figure 6. Ratios of NdFeB volume and back-EMF. 


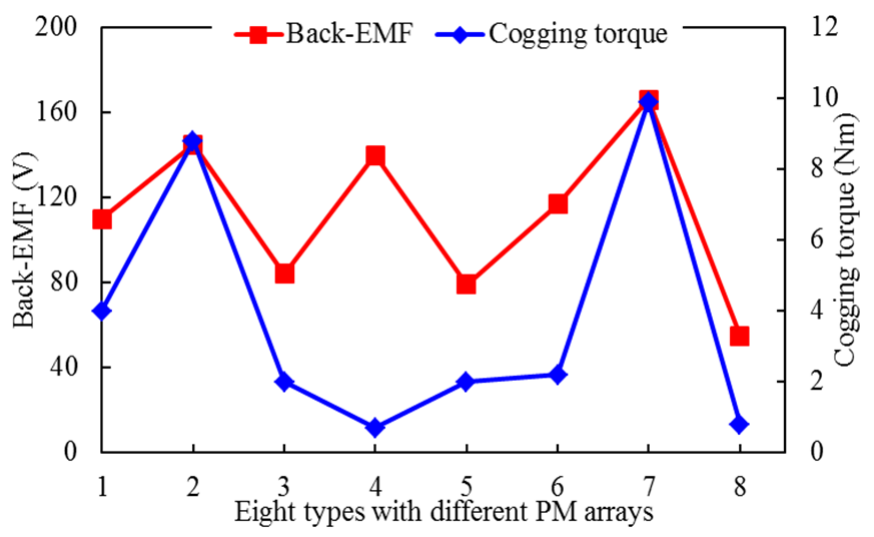

Figure 7. Back-EMF and cogging torque of eight types.

The ferrite has the advantage of anti-demagnetization under high temperatures, whereas $\mathrm{NdFeB}$ does not. Moreover, the stator can obtain better heat dissipate conditions than the rotor. Therefore, in order to maintain the performance of the machine and reduce the possibility of demagnetization, a ferrite magnet is applied to the rotor and an $\mathrm{NdFeB}$ magnet is used in the stator part, namely, type 1 is selected.

Next, some important parameters of the proposed machine are designed. The main design parameters include the stator tooth tip width, the slot opening, the stator PM width and the rotor PM width. In this work, these parameters are analyzed to establish their dependencies and determine their optimal values. Moreover, the sides of the PMs adjacent to the air gap are designed to be straight, which is convenient for processing.

Figures 8 and 9 show the design results of the slot opening of the stator ( $(s b s)$ ). It can be seen that the value of $s b s 0$ has few effects on torque and torque ripple. However, the value of $s b s 0$ has a great influence on the cogging torque. The cogging torque is caused by the interaction between the PMs and the core when the windings are not energized. The variation of $s b s 0$ changes the positional relationship between the teeth and the PMs. According to the results, when the value equals $2.2 \mathrm{~mm}$, the performance is the best. Figures 10 and 11 show the optimization of the width of the middle PM in the stator part. The total width of the iron-cored Halbach array is $6.5 \mathrm{~mm}$ based on the width of the stator tooth. With the increase in the middle PM width, the back-EMF amplitude increases and cogging torque decreases. Taking the torque and torque ripple into account, the value of middle PM width is selected to be $2.7 \mathrm{~mm}$. It should be noted that the variation of the torque ripple is quite different from the cogging torque. This phenomenon will be discussed in the next section.

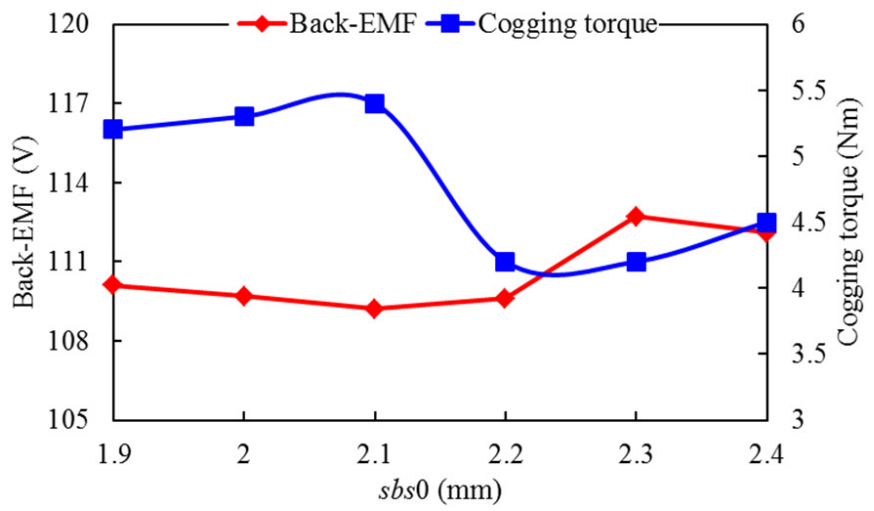

Figure 8. Variations of back-EMF and cogging torque with $s b s 0$. 


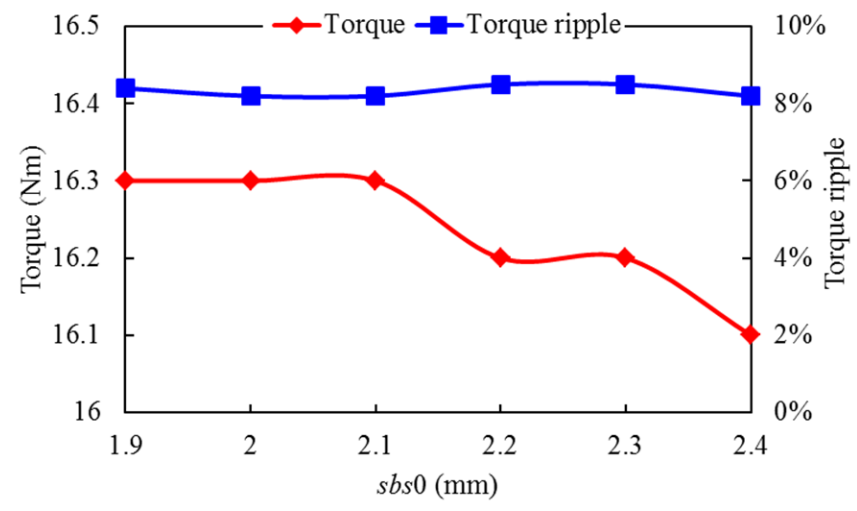

Figure 9. Variations of torque and torque ripple with sbs0.

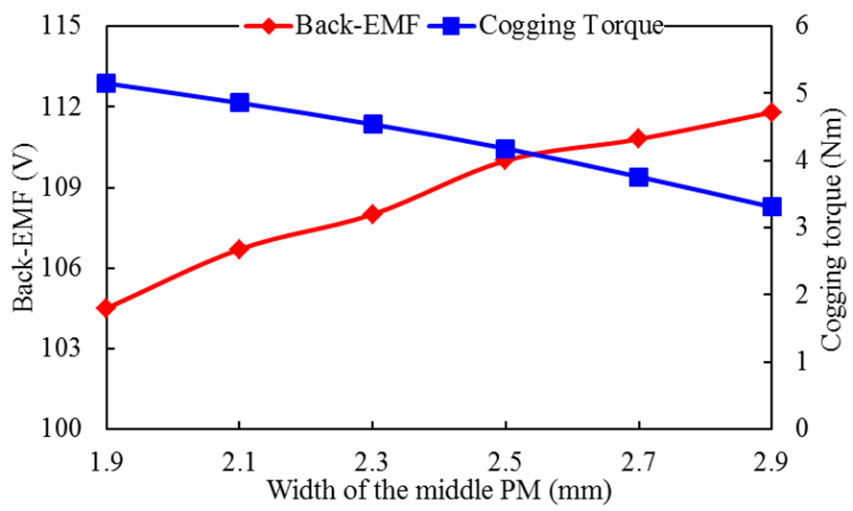

Figure 10. Variations of back-EMF and cogging torque with the width of the middle PM optimization.

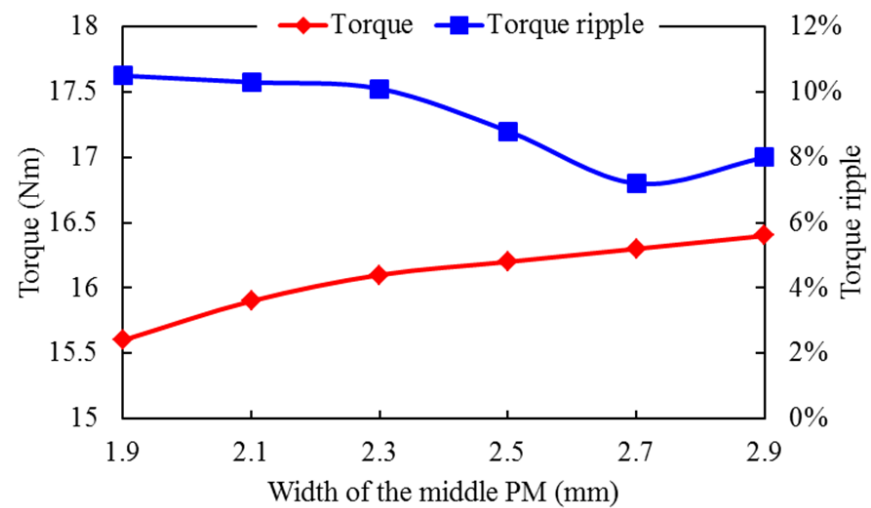

Figure 11. Variations of torque and torque ripple with the width of the middle PM.

Figure 12 shows the optimization of the ferrite magnet size. The cross-sectional shape of the ferrite is a trapezoid. The widths near the air gap and away from the air gap of the trapezoid are optimized. The half-width near the air gap is represented by $r_{a}$ and $r_{b}$ represents the other side. $r_{a}$ ranges from 2.85 to $3.05 \mathrm{~mm}$ and $r_{b}$ ranges from 1.75 to $1.95 \mathrm{~mm}$. Figure 12a shows the back-EMF amplitudes. It can be seen that the amplitudes of the back-EMF range from $106 \mathrm{~V}$ to $112 \mathrm{~V}$. The change in ferrite size has little effect on the back-EMF. Figure 12b shows the average torques. Similar to the amplitude of the back-EMF, the average torque has small changes, which range from $15.8 \mathrm{Nm}$ to $16.2 \mathrm{Nm}$. Figure $12 \mathrm{c}$ shows the torque ripple ratios. It can be seen that torque ripple ranges from $5 \%$ to $15 \%$. To maintain the torque ripple ratio within $10 \%$, considering all the constraints, a set combination of ferrite size is selected. The value of $r_{a}$ and $r_{b}$ are selected to be $2.90 \mathrm{~mm}$ and $1.85 \mathrm{~mm}$, respectively. 


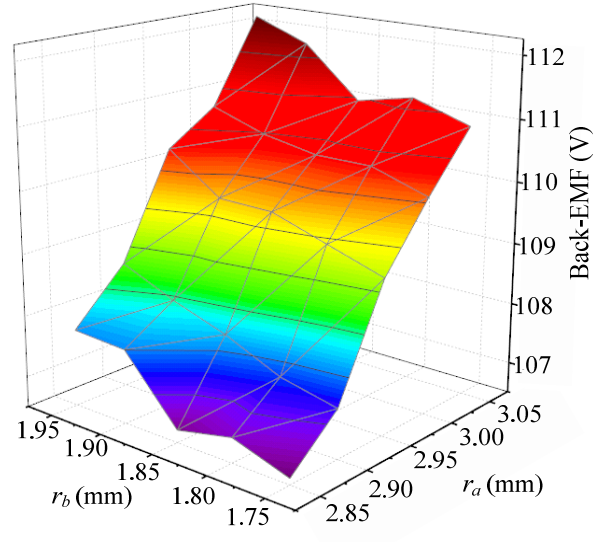

(a)

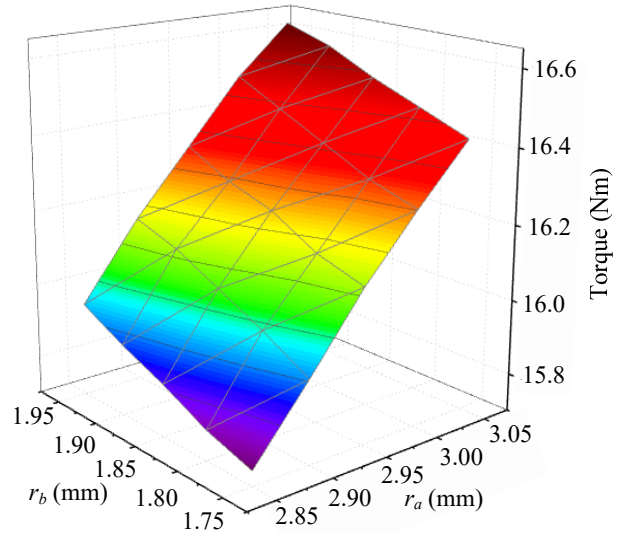

(b)

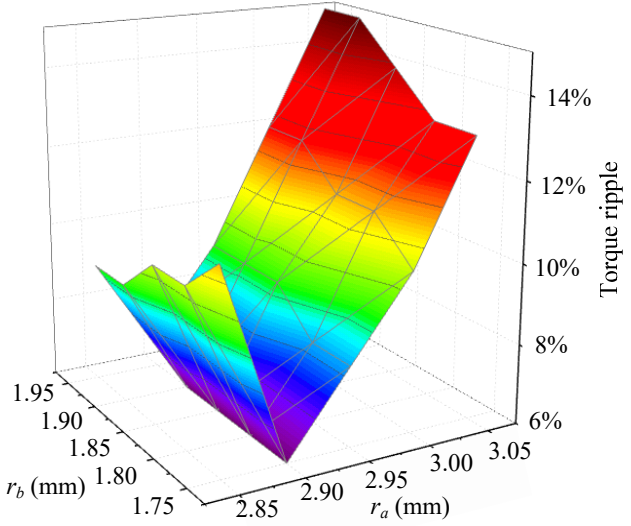

(c)

Figure 12. The optimizations of ferrite size. (a) Back-EMF. (b) Average torque. (c) Torque ripple.

\section{Performance Evaluation}

\subsection{Open-Circuit Field Distributions}

Adopting FEM, the magnetic characteristics are analyzed. Figure 13 shows the magnetic field of the proposed machine. It can be seen that the effective magnetic circuit through the tooth portion is formed. Figure 14 shows the air-gap flux density waveforms of the proposed machine with PM in the stator, the rotor, and both sides. The $x$-axis refers to the mechanical angle and the $y$-axis represents the flux density of the corresponding position. It can be seen that the machine with the PM on both sides has the highest peak 
flux density, and the maximum value of the flux density can reach up to $1.5 \mathrm{~T}$. Figure 15 shows the harmonic spectra of flux density including the above three cases. It can be seen that the most significant harmonics include the 24th, 36th, 4th, 8th and 28th. All harmonics are in line with the modulation effect.

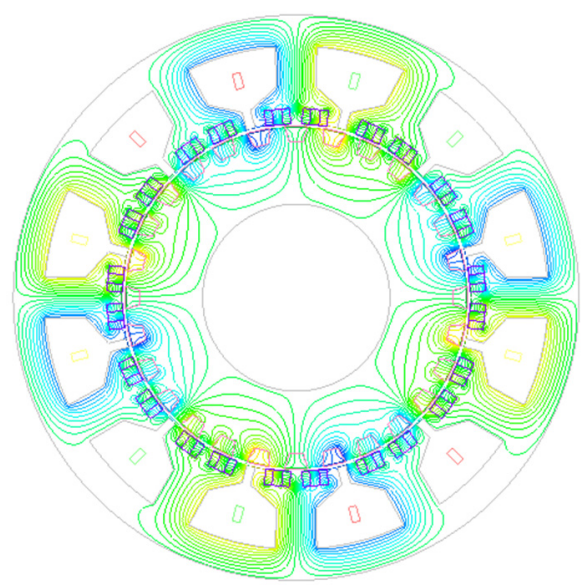

Figure 13. Field distributions at no-load.

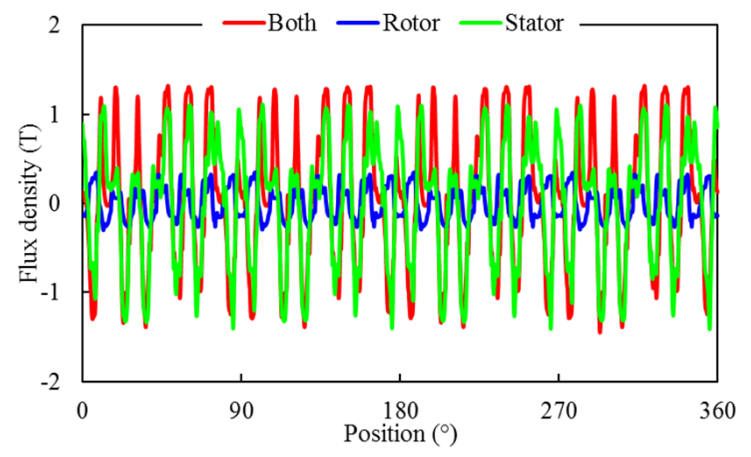

Figure 14. Air-gap flux density.

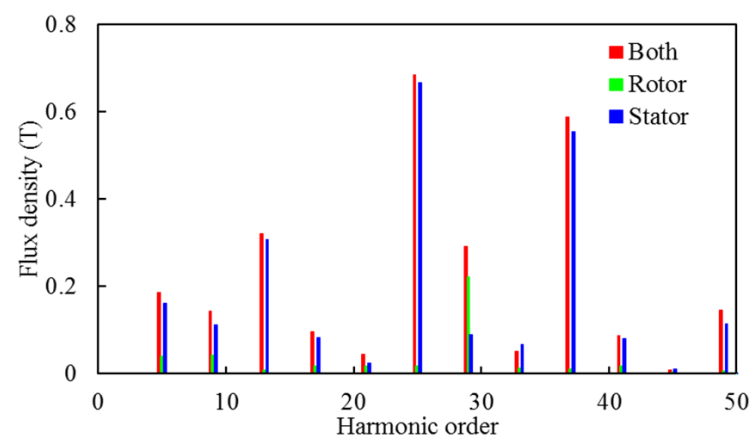

Figure 15. Harmonic spectra of air-gap flux density.

\subsection{Flux Linkage, Back-EMF and Inductance}

The phase back-EMF $E$ can be written as:

$$
E=\frac{d \psi}{d t}=\frac{d \varphi}{d t} v
$$

Therefore, the $E$ is proportional to the rate of change in the flux linkage. In Figure 16, it can be seen that phase flux linkages are asymmetrical while the rate of change of the phase flux linkages is sinusoidal. Therefore, its back-EMFs are sinusoidal and symmetrical, as shown in Figure 17. 


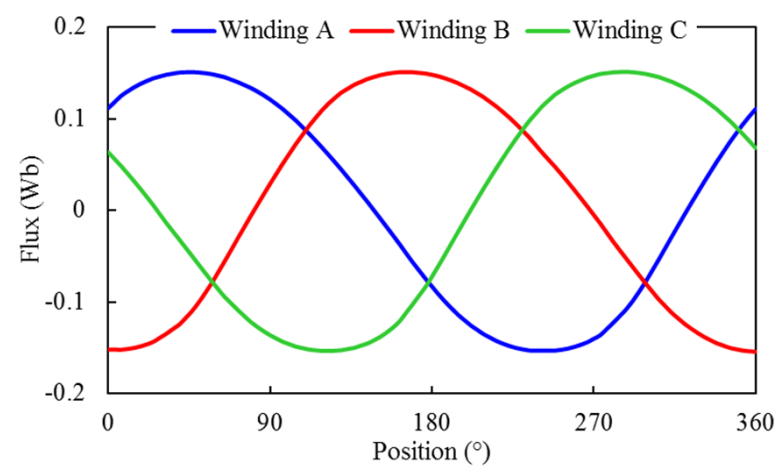

Figure 16. PM flux linkages.

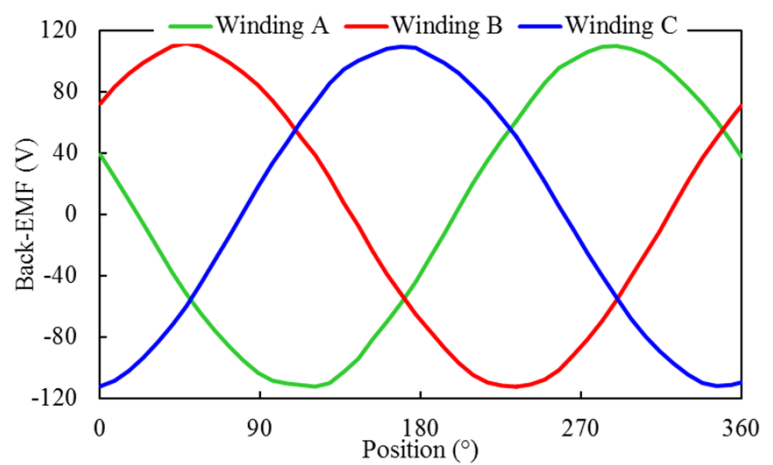

Figure 17. Back-EMF at the speed of $600 \mathrm{r} / \mathrm{min}$.

The self- and mutual-inductances of each phase can be predicted by FEM. For one phase, such as phase A, the self- and mutual-inductances are calculated as:

$$
\begin{aligned}
& L_{a a}=\frac{\psi_{A}\left(I_{c}=I_{b}=0, I_{a}=I\right)-\psi_{A}\left(I_{c}=I_{b}=I_{a}=0\right)}{I} \\
& M_{a c}=\frac{\psi_{C}\left(I_{c}=I_{b}=0, I_{a}=I\right)-\psi_{A}\left(I_{a}=I_{b}=I_{c}=0\right)}{I} \\
& M_{a b}=\frac{\psi_{B}\left(I_{c}=I_{b}=0, I_{a}=I\right)-\psi_{A}\left(I_{a}=I_{b}=I_{c}=0\right)}{I}
\end{aligned}
$$

where $\psi_{a}, \psi_{b}$ and $\psi_{c}$ are the flux linkages of phase A, phase B and phase C. $I_{a}, I_{b}$ and $I_{c}$ represent the current of phase $A$, phase $B$ and phase $C$, respectively. $I$ is the value of the current. Figure 18 compares the predicted self- and mutual-inductances of the proposed machine. The ratio of mutual- and self-inductance of the motor is often used to evaluate the fault-tolerance performance. As can be seen, the virtual value of the self-inductance is much larger than that of the mutual-inductance, which means that the proposed machine has good fault-tolerant performance.

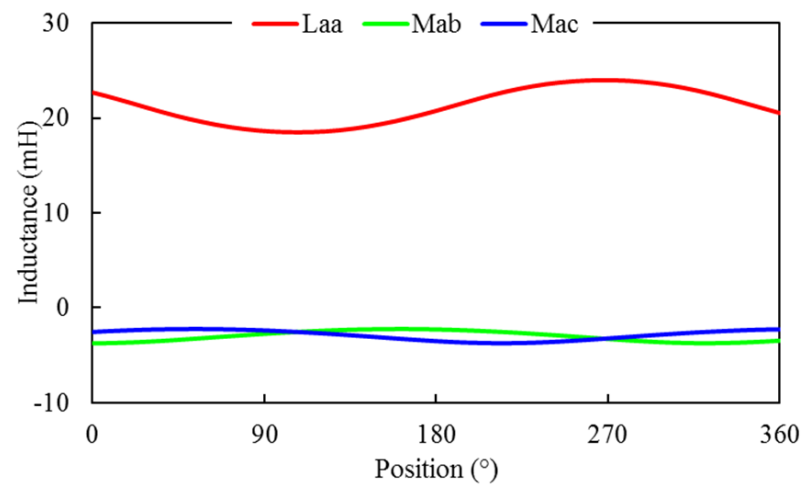

Figure 18. Comparisons of self- and mutual-inductances. 


\subsection{Cogging Torque and Electromagnetic Torque}

The cogging torque of the proposed machine was analyzed above. In addition to the cogging torque, the torque ripple also should be considered in order to obtain a smooth torque output. In this work, the value of the torque ripple ratio needs to be controlled within $10 \%$. The foregoing results show that the point with minimal torque ripple is different from the point with the lowest cogging torque of the proposed machine. This is because the reluctance torque characteristic of the embedded machine affects the torque ripple of the machine. It is advisable to counteract torque ripple by adjusting the cogging torque and the reluctance torque. Figure 19 shows the cogging torque and the reluctance torque waveforms. It can be seen that the cogging torque and the reluctance torque can offset each other effectively. Therefore, the torque ripple can be effectively reduced. Figure 20 shows the torque and the value of average torque $T$ is about $15.7 \mathrm{Nm}$. In Figures 19 and 20, the $x$-axis refers to the electrical angle. According to [42], the torque density TRV can be expressed as (12). At a relatively low electric load of $171.8 \mathrm{~A} / \mathrm{cm}$ and natural cooling conditions, the $T R V$ is $43.0 \mathrm{kNm} / \mathrm{m}^{3}$. In addition, it can be seen that the waveform of torque is very smooth, and the torque ripple ratio is just about $5 \%$.

$$
T R V=\frac{T}{\frac{\pi}{4} D_{\mathrm{ro}}^{2} l_{\mathrm{stk}}}
$$

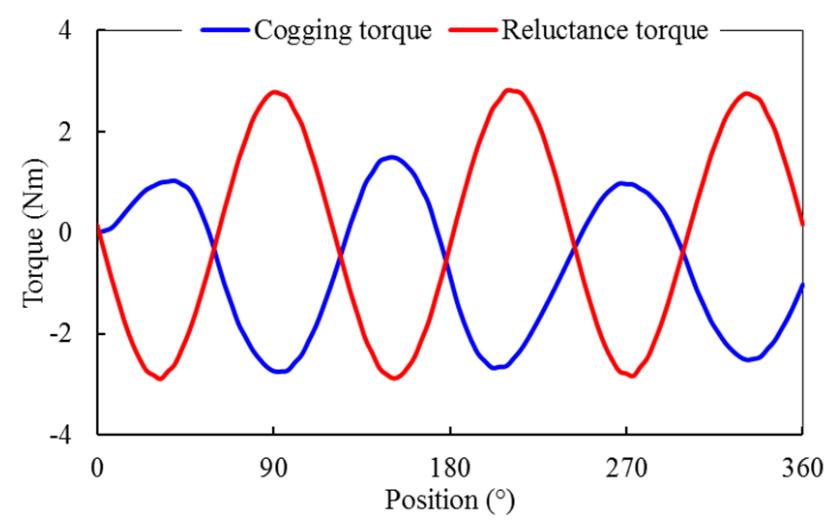

Figure 19. Comparisons of the cogging torque and reluctance torque.

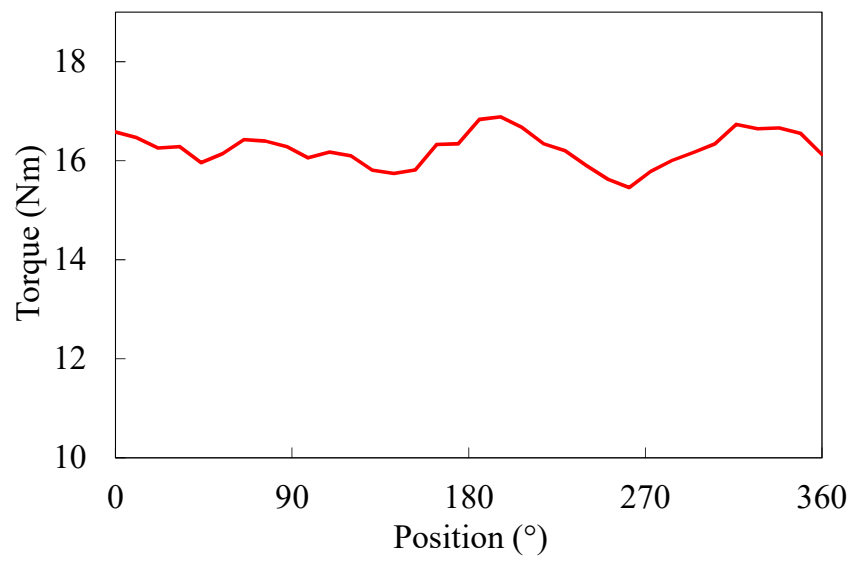

Figure 20. Torque of the proposed machine.

Then, a TRV comparison of the proposed machine and conventional 12-slot eight-pole surface PM machine is listed in Table 2. It can be seen that the proposed machine offers higher TRV under the same electric load. Therefore, the proposed machine has improved torque density. 
Table 2. Torque density comparison of two machines.

\begin{tabular}{|c|c|c|}
\hline Item & Proposed & SPM \\
\hline Outer diameter (mm) & & \\
\hline Stack length (mm) & & \\
\hline Electric load (A/cm) & & \\
\hline Torque density $(\mathrm{kNm} / \mathrm{m} 3)$ & 15.7 & 12.4 \\
\hline
\end{tabular}

\section{Experimental Verification}

A prototype machine was designed and manufactured to validate the theoretical analysis. Figure 21 shows the photographs of the prototype machine and the experimental bench. Figure 21a is the lamination of the stator. The PMs are shown in Figure 21b, while the structure of the rotor is shown in Figure 21c. The experiment bench was built and shown in Figure 21d. It can be seen that the experiment bench consists of a DC machine, torque sensor and HPMV prototype machine. In the no-load condition, the measurement of the back-EMF waveforms is obtained by driving the prototype machine with the DC machine. Then, under the on-load condition, the DC machine as load, the prototype machine can be rotated by the SVPWM control.

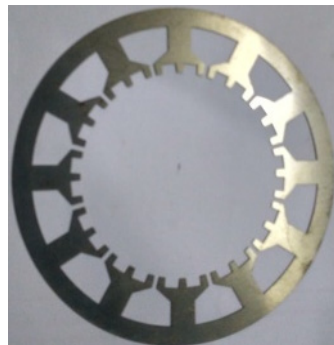

(a)

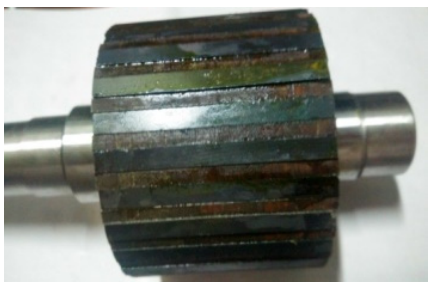

(c)

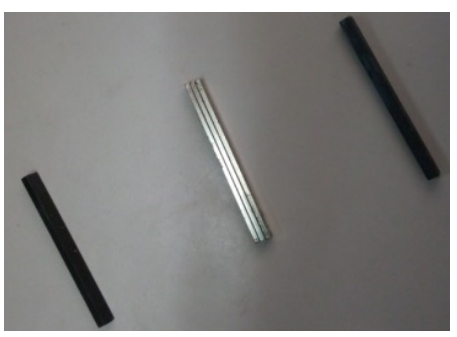

(b)

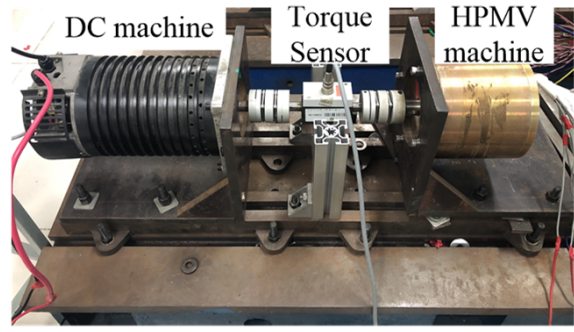

(d)

Figure 21. Prototype of the proposed machine. (a) Stator lamination. (b) Rotor. (c) PMs. (d) Experiment platform.

Figure 22 shows the measured three-phase back-EMF waveforms of the prototype machine at a rated speed of $600 \mathrm{r} / \mathrm{min}$. It can be seen that the three-phase waveforms are sinusoidal and balanced. The back-EMF amplitude calculated by the FEM is $93 \mathrm{~V}$ when the air-gap thickness is $0.6 \mathrm{~mm}$. The amplitude of the back-EMF of the prototype machine is about $83 \mathrm{~V}$. The difference between the experimental results and the simulated results is less than $10 \%$, showing a good agreement. The error is mainly caused by the machining accuracy of the machine and the re-install in the processing. Figure 23 shows the measured loading currents of the experiment. The amplitude loading current is about $7 \mathrm{~A}$, which is the same as the rated current. Figure 24 is the comparison of the torque results of measured and FEM. It can be seen that the torque of the FEM is about $2.2 \mathrm{Nm}$ higher than that of the measured. The error is mainly caused by the processing and frictional loss. 


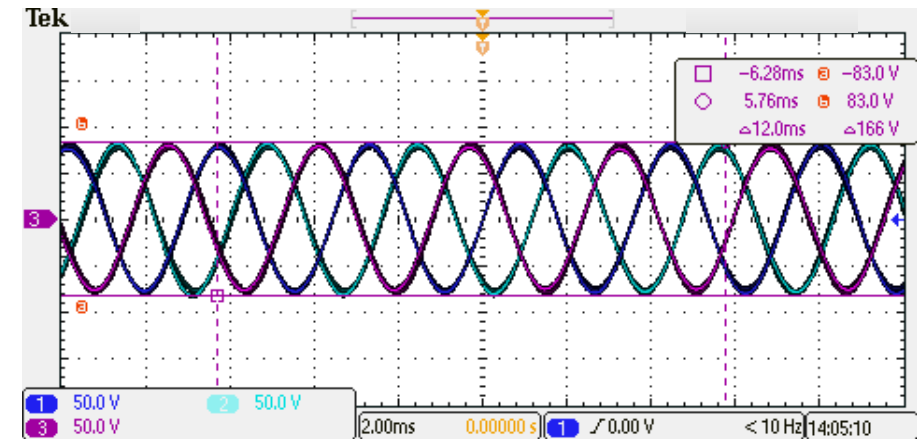

Figure 22. Measured back-EMF at speed of $600 \mathrm{r} / \mathrm{mim}$.

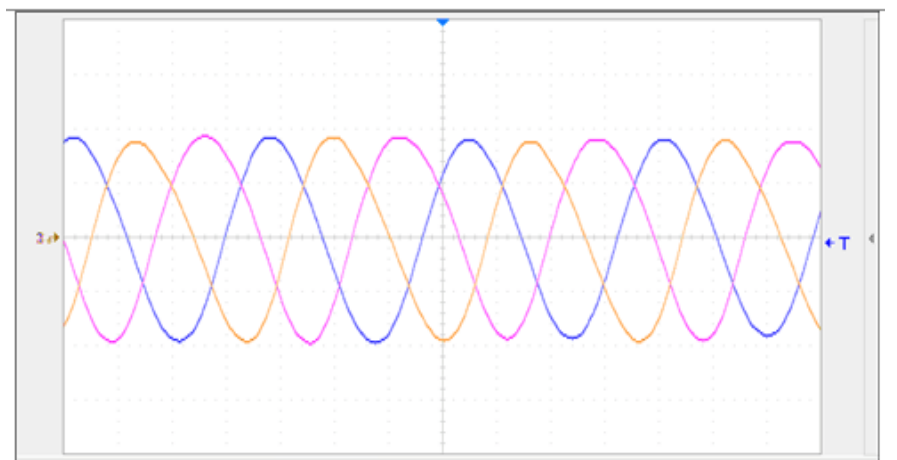

Figure 23. Measured loading currents (4 A/div).

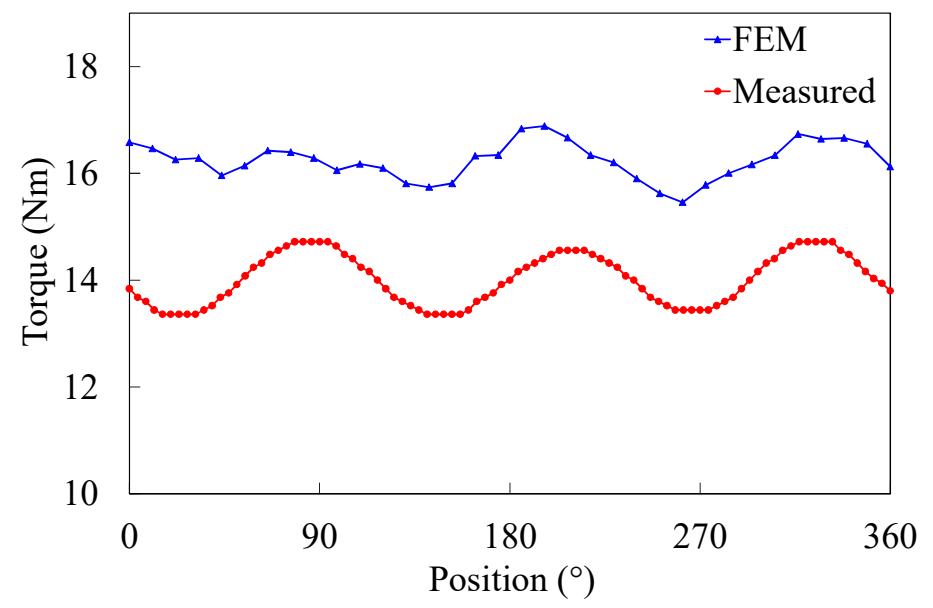

Figure 24. Comparison of the torque results of measured and FEM.

\section{Conclusions}

In order to achieve a high torque density at a reasonable cost, an HPMV machine incorporating expansive rare earth and inexpensive ferrite magnets was designed and analyzed in this paper. The combinations of the stator PMs and rotor PMs were investigated and determined. Then, the electromagnetic performances of the proposed machine were revealed in detail. It can be found that the proposed machine has improved torque density compared with the conventional counterpart. Furthermore, a prototype machine was built and tested. Both simulation and experimental results on the machine have verified the theoretical analysis. Due to the special dual PM structure, the HPMV machine has complex magnetic field distribution. Therefore, the noise and vibration of the machine need to be studied in the future. 


\begin{abstract}
Author Contributions: Conceptualization, M.K. and L.X.; manufacturing, M.K. and L.X.; software, L.X. and X.Z.; validation; J.J. and X.Z.; writing—original draft preparation, M.K.; writing-review and editing, J.J. and L.X.; supervision, J.J. All authors have read and agreed to the published version of the manuscript.

Funding: This work was supported in part by the National Natural Science Foundation of China (51977099 and 52177044), by the Hong Kong Scholars Program (XJ2019031), by the Natural Science Foundation of Jiangsu Higher Education Institutions (21KJA470004) and by the Priority Academic Program Development of Jiangsu Higher Education Institutions.
\end{abstract}

Institutional Review Board Statement: Not applicable.

Informed Consent Statement: Not applicable.

Data Availability Statement: Not applicable.

Conflicts of Interest: The authors declare no conflict of interest.

\title{
References
}

1. Li, X.; Xue, Z.; Yan, X.; Zhang, L.; Ma, W.; Hua, W. Low-complexity multivector-based model predictive torque control for PMSM with voltage preselection. IEEE Trans. Power Electron. 2021, 36, 11726-11738. [CrossRef]

2. Jiang, T.; Zhao, W.; Xu, L.; Ji, J. A novel parallel hybrid excitation field modulated machine with efficient utilization of multiworking harmonics. IEEE Trans. Ind. Electron. 2022, 69, 1177-1188. [CrossRef]

3. Mao, Y.; Niu, S.; Wang, Q. Design and optimization of a slot-PM-assisted doubly-salient machine based on saturation assuaging. Chin. J. Electr. Eng. 2021, 7, 65-72. [CrossRef]

4. Wang, B.; Wang, J.; Griffo, A.; Sen, B. A general modeling technique for a triple redundant 3×3-phase PMA SynRM. IEEE Trans. Ind. Electron. 2018, 65, 9068-9078. [CrossRef]

5. Shi, Y.; Ching, T.W. Power factor analysis of dual-stator permanent magnet vernier motor with consideration on turn-number assignment of inner and outer stator windings. IEEE Trans. Magn. 2021, 57, 8200405. [CrossRef]

6. Zhu, X.; Ji, J.; Xu, L.; Kang, M. Design and analysis of dual-stator PM vernier linear machine with PMs surface-mounted on the mover. IEEE Trans. Appl. Supercond. 2018, 28, 5201605. [CrossRef]

7. Wang, S.; Zhang, X.; Zhao, X.; Niu, S.; Fu, W. A Novel slot-pm assisted complementary-rotor doubly-salient machine with enhanced torque performance. IEEE Trans. Ind. Electron. 2021. [CrossRef]

8. Zhao, X.; Niu, S.; Fu, W. Design of a novel parallel-hybrid-excited dual-PM machine based on armature harmonics diversity for electric vehicle propulsion. IEEE Trans. Ind. Electron 2019, 66, 4209-4219. [CrossRef]

9. Xu, L.; Liu, G.H.; Zhao, W.X.; Ji, J.H.; Zhou, H.W.; Zhao, W.X.; Jiang, T.T. Quantitative comparison of integral and fractional slot permanent magnet vernier motors. IEEE Trans. Energy Convers. 2015, 30, 1483-1495. [CrossRef]

10. Sheng, T.T.; Niu, S.X. Design of doubly complementary stator-PM machine with high magnet utilization factor for low cost applications. IEEE Trans. Energy Convers. 2018, 33, 567-575. [CrossRef]

11. Zhao, X.; Niu, S. A new slot-PM vernier reluctance machine with enhanced zero-sequence current excitation for electric vehicle propulsion. IEEE Trans. Ind. Electron. 2020, 67, 3528-3539. [CrossRef]

12. Xu, L.; Zhao, W.; Li, R.; Niu, S. Analysis of rotor losses in permanent magnet vernier machines. IEEE Trans. Ind. Electron. 2022, 69, 1224-1234. [CrossRef]

13. Du, K.; Xu, L.; Zhao, W.; Liu, G. Analysis and design of a fault-tolerant permanent magnet vernier machine with improved power factor. IEEE Trans. Ind. Electron. 2022, 69, 4353-4363. [CrossRef]

14. Xu, L.; Wu, W.; Zhao, W. Airgap magnetic field harmonic synergetic optimization approach for power factor improvement of PM vernier machines. IEEE Trans. Ind. Electron. 2021. [CrossRef]

15. Xu, L.; Liu, G.H.; Zhao, W.X.; Ji, J.H.; Fan, X. High-Performance fault tolerant halbach permanent magnet vernier machines for safety-critical applications. IEEE Trans. Magn. 2016, 52, 8104704. [CrossRef]

16. Jiang, S.; Liu, G.; Zhao, W.; Xu, L.; Chen, Q. Modeling and analysis of spoke-type permanent magnet vernier machine based on equivalent magnetic network method. Chin. J. Electr. Eng. 2018, 4, 96-103.

17. Gao, Y.; Qu, R.; Li, D.; Chen, F. Force ripple minimization of a linear vernier permanent magnet machine for direct-drive servo applications. IEEE Trans. Magn. 2017, 53, 7001905. [CrossRef]

18. Xu, L.; Liu, G.; Zhao, W.; Yang, X.; Cheng, R. Hybrid stator design of fault-tolerant permanent-magnet vernier machines for direct-drive applications. IEEE Trans. Ind. Electron. 2017, 64, 179-190. [CrossRef]

19. Li, J.G.; Chau, K.T.; Jiang, J.Z.; Liu, C.H.; Li, W.L. A new permanent-magnet vernier machine for wind power generation. IEEE Trans. Magn. 2010, 46, 1475-1478. [CrossRef]

20. Ishizaki, A.; Tanaka, T.; Takasaki, K.; Nishikata, S. Theory and optimum design of PM vernier machine. In Proceedings of the 1995 Seventh International Conference on Electrical Machines and Drives, Durham, UK, 11-13 September 1995; pp. $208-212$.

21. Park, J.-H.; Lukman, G.F.; Kang, D.-H.; Ahn, J.-W. Performance characteristics of a dual-stator, spoke-type permanent magnet vernier machine with support bar. Energies 2021, 14, 1068. [CrossRef] 
22. Jia, C.; Xu, L.; Ji, J.; Zhao, W. Comparative study of partitioned stator flux-modulation motors with different permanent magnet arrays. Int. J. Appl. Electromagn. Mech. 2021, 11, 387-405. [CrossRef]

23. Li, D.W.; Qu, R.H.; Lipo, T.A. High power factor vernier permanent magnet machines. IEEE Trans. Ind. Appl. 2014, 50, 3664-3674. [CrossRef]

24. Xu, L.; Zhao, W.; Liu, G.; Song, C. Design optimization of a spoke-type permanent-magnet vernier machine for torque density and power factor improvement. IEEE Trans. Veh. Technol. 2019, 68, 3446-3456. [CrossRef]

25. Wang, B.; Hu, J.; Hua, W.; Wang, Z. Fault operation analysis of a triple-redundant three-phase PMA-SynRM for EV application IEEE Trans. Transp. Electrif. 2021, 7, 183-192. [CrossRef]

26. Li, X.; Wang, X.; Yu, S. Design and analysis of a novel transverse-flux tubular linear switched reluctance machine for minimizing force ripple. IEEE Trans. Transp. Electrif. 2021, 7, 741-753. [CrossRef]

27. Xu, L.; Liu, G.; Zhao, W.; Ji, J.; Zhou, H.; Jiang, T. Design and analysis of a new linear wound-field flux reversal machine based on magnetic gear effect. IEEE Trans. Magn. 2015, 51, 8205004. [CrossRef]

28. Jiang, T.; Zhao, W.; Xu, L.; Wang, H. Investigation into multitoothed distribution design for magnetless doubly salient machine. IEEE Trans. Transp. Electrif. 2021, 7, 2787-2797. [CrossRef]

29. Chung, S.; Kim, J.; Chun, Y.; Woo, B.; Hong, D. Fractional slot concentrated winding PMSM with consequent magnet. IEEE Trans. Energy Convers. 2015, 3, 103-109. [CrossRef]

30. Dorrell, D.G.; Knight, A.M.; Evans, L.; Popescu, M. Analysis and design techniques applied to hybrid vehicle drives machinesassessment of alternative IPM and induction motor topologies. IEEE Trans. Ind. Electron. 2012, 59, 3690-3699. [CrossRef]

31. Boldea, I.; Tutelea, L.N.; Parsa, L.; Dorrel, D.G. Automotive electric propulsion systems with reduced or no permanent magnets: An overview. IEEE Trans. Ind. Electron. 2014, 61, 5696-5711. [CrossRef]

32. Chiba, A.; Kiyota, K.; Hoshi, N.; Takemoto, M.; Ogasawara, S. Development of a rare-earth-free SR motor with high torque density for hybrid vehicles. IEEE Trans. Energy Convers. 2015, 30, 175-182. [CrossRef]

33. Chen, Q.; Liu, G.H.; Zhao, W.X.; Shao, M.M.; Liu, Z.M. Design and analysis of the new high reliability motors with hybrid permanent magnet materials. IEEE Trans. Magn. 2015, 50, 8207010. [CrossRef]

34. Rehman, A.; Kim, B. Characteristics analysis of consequent pole ferrite magnet vernier machine using novel equivalent magnetic circuit. IEEE J. Emerg. Sel. Top. Power Electron. 2021. [CrossRef]

35. Xu, L.; Zhao, W.; Liu, G.; Ji, J.; Niu, S. A novel dual-permanent-magnet-excited machine with non-uniformly distributed permanent-magnets and flux modulation poles on the stator. IEEE Trans. Veh. Technol. 2020, 69, 7104-7115. [CrossRef]

36. Gao, Y.; Doppelbauer, M.; Qu, R.; Li, D.; Ding, H. Synthesis of a flux modulation machine with permanent magnets on both stator and rotor. IEEE Trans. Ind. Appl. 2021, 57, 294-305. [CrossRef]

37. Gao, Y.; Doppelbauer, M.; Ou, J.; Qu, R. Design of a Double-Side Flux Modulation Permanent Magnet Machine for Servo Application. IEEE J. Emerg. Sel. Top. Power Electron. 2021. [CrossRef]

38. Shi, Y.; Jian, L.; Ching, T.W. Quantitative identification of airgap flux density harmonics contributing to back-emf in dualpermanent-magnet-excited machine. IEEE Trans. Magn. 2021. [CrossRef]

39. Li, Y.; Yang, H.; Lin, H.; Liu, W.; Zhao, X. Torque generation mechanism and performance evaluation of a dual-sided pm machine with stator U-shaped magnets. IEEE Trans. Ind. Appl. 2021, 58, 250-260. [CrossRef]

40. Lin, Q.; Niu, S.; Cai, F.; Fu, W.; Shang, L. Design and optimization of a novel dual-PM machine for electric vehicle applications. IEEE Trans. Veh. Technol. 2020, 69, 14391-14400. [CrossRef]

41. Shi, Y.; Jian, L. A novel dual-permanent-magnet-excited machine with flux strengthening effect for low-speed large-torque applications. Energies 2018, 11, 153. [CrossRef]

42. Hendershot, J.R., Jr.; Miller, T.J.E. Design of Brushless Permanent Magnet Motors, 1st ed.; Oxford University Press: New York, NY, USA, 1995 